\title{
Atributos de desempenho industrial e qualidade de sementes em aveia branca em função da disponibilzação da adubação nitrogenada
}

\author{
Grain quality parameters and seeds quality in oat in relation to \\ nitrogen fertilization availability
}

\author{
Eliane Maria Kolchinski ${ }^{1}$ Luis Osmar Braga Schuch ${ }^{2}$
}

\begin{abstract}
O presente trabalho teve como objetivo avaliar os RESUMO efeitos da adubação nitrogenada sobre atributos de desempenho industrial e na qualidade fisiológica de sementes em aveia branca (Avena sativa L.). O ensaio constou da combinação fatorial de cultivares (CTC 5, UFRGS 15, UFRGS 19 e UPF 18) e disponibilizações de $N$ (ausência de aplicação de $N$; aplicação de $48 \mathrm{~kg} \mathrm{ha}^{-1}$ na semeadura; aplicação de $16 \mathrm{~kg} \mathrm{ha-}$ ${ }^{1}$ na semeadura e $32 \mathrm{~kg} \mathrm{ha}^{-1}$ no perfilhamento; aplicação de

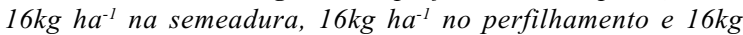
ha $a^{-1}$ na emergência da panícula). As disponibilizações de $N$ não afetaram o peso do hectolitro, o rendimento industrial $e$ a qualidade fisiológica das sementes. A aplicação de $N$ na emissão da panícula elevou a concentração de proteína nas cariopses.
\end{abstract}

Palavras-chave: Avena sativa L., nitrogênio, proteína, peso hectolitrico, rendimento industrial.

\section{ABSTRACT}

The objective of this work was to evaluate the effect of the nitrogen ( $N$ ) fertilization timing on grain quality parameters and physiological quality of seeds of oat (Avena sativa L.). The experiment consisted of combinations of cultivars (CTC 5, UFRGS 15, UFRGS 19, UPF 18) and $N$ fertilizer availability (no added $N ; 48 \mathrm{~kg} \mathrm{~N} \mathrm{ha}^{-1}$ at sowing; $16 \mathrm{~kg} \mathrm{~N} \mathrm{ha}^{-1}$ at sowing and $32 \mathrm{~kg} \mathrm{~N} \mathrm{ha}^{-1}$ at tillering; and, $16 \mathrm{~kg} N \mathrm{ha}^{-1}$ at sowing, $16 \mathrm{~kg} \mathrm{~N} \mathrm{ha}^{-1}$ at tillering and $16 \mathrm{~kg} N \mathrm{ha}^{-1}$ at panicle emergence). Test weight, caryopsis percentage and physiological quality of seeds, were not affected the by timing and split of $N$ fertilizer applications. Applying $N$ fertilizer at panicle emergence increased the protein concentration in the caryopsis. Key words: Avena sativa L., nitrogen, protein, test weight,
caryopsis percentage.

A aplicação da adubação nitrogenada em cobertura na cultura da aveia nos Estados do Rio Grande do Sul e Santa Catarina é recomendada para o período de início do perfilhamento. No entanto, tem sido relatado que a disponibilidade de $\mathrm{N}$ em estádios de desenvolvimento posteriores tem apresentado efeitos positivos na qualidade de grãos. Segundo KELLING \& FIXEN (1992) aplicações de N no início do estágio vegetativo aumentam o rendimento de grãos, enquanto em estágios mais avançados aumentam a taxa de proteína no grão. Segundo MENGEL \& KIRKBY (1982), em cereais, as sínteses de proteína e de amido competem por fotossintetizados durante o período de enchimento de grãos, sendo que, quando a necessidade de $\mathrm{N}$ para o rendimento é satisfeita, o $\mathrm{N}$ é usado para melhorar a concentração de proteína no grão. Desta forma, se o suprimento de $\mathrm{N}$ é abundante nesta fase, alta proporção de fotossintetizados são convertidos em proteínas. ALCOZ et al. (1993) do trigo observaram maior concentração de $\mathrm{N}$ no grão, com a aplicação da adubação nitrogenada na fase de emissão da panícula.

Resultados de pesquisa demonstram que o teor de proteína tem se relacionado positivamente ao vigor das sementes (CARVALHO \& NAKAGAWA, 1988; SÁ, 1994). No entanto, as respostas podem variar

\footnotetext{
${ }^{1}$ Engenheiro Agrônomo, MSc., Faculdade de Agronomia "Eliseu Maciel”, Universidade Federal de Pelotas (UFPel), Pelotas, RS. ${ }^{2}$ Engenheiro Agrônomo, Doutor, Professor, Departamento de Fitotecnia, Faculdade de Agronomia "Eliseu Maciel", UFPel, CP
} 354, 96001-970, Pelotas, RS. E-mail: lobs@ufpel.tche.br. Autor para correspondência. 
em função das condições do solo, de clima, momento de aplicação do $\mathrm{N}$, época de semeadura, cultivar ou teste empregado para avaliar a qualidade fisiológica (NAKAGAWA et al.,1994; SÁ, 1994).

O presente trabalho teve como objetivo avaliar os efeitos da disponibilização da adubação nitrogenada, na qualidade de grãos e de sementes em cultivares de aveia branca.

Os tratamentos em combinação fatorial constaram de quatro cultivares de aveia branca (CTC5, UFRGS 15, UFRGS 19, UPF 18) e quatro disponibilizações de $\mathrm{N}$ (ausência de aplicação de $\mathrm{N}$; aplicação de $48 \mathrm{~kg} \mathrm{ha}^{-1}$ na semeadura; aplicação de $16 \mathrm{~kg}$ $\mathrm{ha}^{-1}$ na semeadura e $32 \mathrm{~kg} \mathrm{ha}^{-1}$ no perfilhamento; aplicação de $16 \mathrm{~kg} \mathrm{ha}^{-1}$ na semeadura, $16 \mathrm{~kg} \mathrm{ha}^{-1}$ no perfilhamento e $16 \mathrm{~kg} \mathrm{ha}^{-1}$ na emergência da panícula). $\mathrm{O} \mathrm{N}$ foi aplicado na forma de nitrato de cálcio. $\mathrm{O}$ delineamento experimental utilizado foi de blocos ao acaso com três repetições.

$\mathrm{O}$ experimento foi conduzido em solo Argissolo Amarelo eutrófico típico, que apresentava as seguintes características: teor de argila: $240 \mathrm{~g} \mathrm{~kg}^{-1}$; Índice SMP: 7,0; MO: 26,7 $\mathrm{g} \mathrm{dm}^{-3}$; P: $15 \mathrm{mg} \mathrm{dm}^{-3}$; $\mathrm{K}$ : $78 \mathrm{mg} \mathrm{dm}^{-3}$. O preparo do solo foi de forma convencional e além da adubação nitrogenada aplicou-se $200 \mathrm{~kg} \mathrm{ha}^{-1}$ da fórmula (N-P-K) 0-20-20. A semeadura foi realizada em 07/07/1999, visando atingir uma população de 300 plantas $\mathrm{m}^{-2}$. As aplicações do $\mathrm{N}$ em cobertura foram realizadas no perfilhamento $(50 \%$ das plantas com um perfilho) e na emergência das panículas $(50 \%$ das plantas com panícula emergida), conforme o tratamento considerado.

Por ocasião da maturação, foram colhidas as áreas úteis das parcelas e avaliados a qualidade industrial de grãos, através do peso do hectolitro, do rendimento industrial, do teor de proteína nos grãos com casca e nas cariopses; e a qualidade fisiológica das sementes através dos testes de germinação (BRASIL, 1992) e envelhecimento acelerado (MARCOS FILHO, 1999). Os teores de proteína nos grãos foram determinados a partir de valores de $\mathrm{N}$ total, obtidos através do método micro-Kjeldahl, empregando a constante 6,25. Com base na concentração de proteína nos grãos com casca e rendimento de grãos, foi calculada a produção de proteína $\left(\mathrm{kg} \mathrm{ha}^{-1}\right)$.

Os dados experimentais foram submetidos à análise de variância e os efeitos dos tratamentos avaliados por comparações de médias, pelo teste de Duncan em nível de 5\% de significância.

A análise de variância demonstrou que não ocorreram interações entre cultivares e disponibilizações de $\mathrm{N}$ para nenhuma das variáveis analisadas. Assim são apresentados apenas os efeitos simples dos tratamentos (Tabela 1).

Os resultados demonstram que não ocorreram diferenças significativas no peso hectolítrico

Tabela 1 - Componentes de qualidade industrial, rendimento de proteína e qualidade de sementes em cultivares de aveia branca, submetidas a épocas e fracionamentos da adubação nitrogenada.

\begin{tabular}{|c|c|c|c|c|c|c|c|}
\hline \multirow{2}{*}{ Tratamentos } & \multirow{2}{*}{$\begin{array}{c}\text { Peso } \\
\text { hectolitrico }\end{array}$} & \multicolumn{2}{|c|}{ Conc. de proteina } & \multicolumn{2}{|c|}{ Rendimento } & \multirow{2}{*}{ Germinação } & \multirow{2}{*}{ Vigor } \\
\hline & & grãos c/ casca & cariopses & industrial & de proteína & & \\
\hline Disponibiliz. de $\mathrm{N}^{*}$ & $\mathrm{~kg} \mathrm{hL}^{-1}$ & & $\%$ & & $\mathrm{~kg} \mathrm{ha}^{-1}$ & $\%$ & \\
\hline No & $51,4 \mathrm{a}^{* *}$ & $10,3 \mathrm{ab}$ & $12,9 \mathrm{~b}$ & $69,8 \mathrm{a}$ & $205,7 \mathrm{~b}$ & $97 \mathrm{a}$ & $84 \mathrm{a}$ \\
\hline $\mathrm{N} 1$ & $50,1 \mathrm{a}$ & $9,5 \mathrm{~b}$ & $13,4 \mathrm{~b}$ & $68,0 \mathrm{a}$ & $244,9 \mathrm{~b}$ & $98 \mathrm{a}$ & $84 \mathrm{a}$ \\
\hline N2 & $50,4 \mathrm{a}$ & $9,9 \mathrm{ab}$ & $13,7 \mathrm{~b}$ & $67,1 \mathrm{a}$ & 301,9 a & $98 \mathrm{a}$ & $88 \mathrm{a}$ \\
\hline N3 & $51,2 \mathrm{a}$ & $10,7 \mathrm{a}$ & $15,1 \mathrm{a}$ & $69,0 \mathrm{a}$ & 302,2 a & 99 a & $84 \mathrm{a}$ \\
\hline \multicolumn{8}{|l|}{ Cultivares } \\
\hline CTC 5 & 53,7 a & $10,2 \mathrm{a}$ & $13,7 \mathrm{a}$ & $71,7 \mathrm{a}$ & $243,8 \mathrm{~b}$ & $98 \mathrm{~b}$ & $78 \mathrm{c}$ \\
\hline UFRGS15 & $46,0 \quad \mathrm{c}$ & $9,8 \mathrm{a}$ & $13,3 \mathrm{a}$ & $67,6 \mathrm{bc}$ & $237,6 \mathrm{~b}$ & $97 \mathrm{~b}$ & $87 \mathrm{ab}$ \\
\hline UFRGS19 & $51,9 \mathrm{~b}$ & $10,3 \mathrm{a}$ & $14,2 \mathrm{a}$ & $69,6 \mathrm{ab}$ & 296,2 a & $97 \mathrm{~b}$ & $83 \mathrm{bc}$ \\
\hline UPF 18 & $51,4 \mathrm{~b}$ & $10,0 \mathrm{a}$ & $13,8 \mathrm{a}$ & $65,0 \mathrm{c}$ & $277,1 \mathrm{ab}$ & $100 \mathrm{a}$ & $92 \mathrm{a}$ \\
\hline $\mathrm{CV}(\%)$ & & & & & & & \\
\hline
\end{tabular}

No - ausência de aplicação de N; N1 - aplicação de $48 \mathrm{~kg} \mathrm{ha}^{-1}$ na semeadura; N2 - aplicação de $16 \mathrm{~kg} \mathrm{ha}^{-1}$ na semeadura e $32 \mathrm{~kg}$ ha ${ }^{-1}$ no perfilhamento; $\mathrm{N} 3$ - aplicação de $16 \mathrm{~kg} \mathrm{ha}^{-1}$ na semeadura, $16 \mathrm{~kg} \mathrm{ha}^{-1}$ no perfilhamento e $16 \mathrm{~kg} \mathrm{ha}^{-1}$ na emergência da panícula.

${ }^{* *}$ Médias seguidas pela mesma letra na coluna e dentro de cada fator não diferem entre si pelo teste de Duncan em nível de $5 \%$ de significância.

Ciência Rural, v. 33, n. 3, mai-jun, 2003. 
entre a ausência e a aplicação da adubação nitrogenada. Esse comportamento pode ser atribuído ao fato de que o peso de grãos normalmente não é modificado, ou então, é reduzido pelo acréscimo na disponibilização de N (MARSHALL et al., 1992), em função do aumento no número de grãos por panícula e/ou panículas por unidade de área. Considerando que o peso de grãos é determinado pela disponibilidade de assimilados durante o período de enchimento de grãos (GARDNER et al., 1985) esperava-se que a variação na disponibilização da adubação nitrogenada afetaria o peso hectolítrico, no entanto não foi constatado diferença significativa entre as épocas de aplicação.

A aplicação de parte da adubação nitrogenada na emissão da panícula provocou elevação na concentração de proteína nas cariopses. Já para concentração de proteína nos grãos com casca, houve diferença significativa somente em relação à aplicação total do $\mathrm{N}$ na semeadura.

Os maiores rendimentos de proteína ocorreram no fracionamento da aplicação do N (duas e três épocas). Este comportamento esteve associado aos dois componentes envolvidos no rendimento de proteína, a concentração de proteína (grãos com casca) e o rendimento de grãos (dados não apresentados). As disponibilizações de $\mathrm{N}$ apresentaram efeitos similares sobre o rendimento industrial.

As diferentes épocas e fracionamento da aplicação da adubação nitrogenada não afetaram a germinação e o vigor das sementes. NAKAGAWA et al. (1994), testando épocas e parcelamentos de aplicação de $\mathrm{N}$ em aveia preta, também não observaram efeito sobre a qualidade fisiológica das sementes.

\section{REFERÊNCIAS BIBLIOGRÁFICAS}

ALCOZ, M.M.; HONS, F.M.; HABY, V.A. Nitrogen fertilization timing effect on wheat production, nitrogen uptake efficiency and residual soil nitrogen. Agronomy Journal, v. 85, p.1198$1203,1993$.

BRASIL. Ministério da Agricultura e Reforma Agrária. Secretaria Nacional de Defesa Agropecuária. Regras para Análise de Sementes. Brasilia, 1992. 365p.

CARVAlho, N.M;, NAKAGAWA, J. Sementes, ciência, tecnologia e produção. 3.ed. Campinas : Fundação Cargill, 1988. 424p.

GARDNER, F.P.; PEARCE, R.B.; MITCHELL, R.L. Physiology of crop plants. Ames : Iowa State University, 1985. 321p.

KELLING, K.A.; FIXEN, P.E. Soil and nutrient requeriments for oat production. In: MARSHALL, H.G.; SORRELIS, M.E. (Eds). Oat science and technology. Madison : ASA/CSSA (Agronomy, 31), 1992. Cap.6. p.165-190.

MARCOS FILHO, J. Testes de envelhecimento acelerado. In: KRZYZANOWSKI, F.C.; VIEIRA, R.D.; FRANÇA NETO, J. de B. Vigor de sementes: conceitos e testes. Londrina: ABRATES, 1999. Cap.3, p.1-24.

MARSHALL, H.G.; McDANIEL, M.E.; CREGGER, L.M. Cultural practices for growing oat in the United States. In: MARSHALL, H.G.; SORRELIS, M.E. (Eds). Oat science and technology. Madison : ASA/CSSA, 1992. Cap.7, p.191-221. (Agronomy, 31).

MENGEL, K.; KIRKBY, E.A. Principles of plant nutrition. 3.ed. Worblaufen-Bern/Switzerland : International Potash Institute, 1982. $655 \mathrm{p}$.

NAKAGAWA, J. et al. Produção e qualidade de aveia preta (Avena strigosa Schreb) em função da adubação nitrogenada. Revista Brasileira de Sementes, Brasília, v.16, n.1, p.95101, 1994.

SÁ, M.E. de. Importância da adubação nitrogenada na qualidade de sementes. In: SÁ, M.E.; BUZZETTI, S. Importância da adubação na qualidade dos produtos agrícolas. São Paulo: Icone, 1994. Cap.4, p.65-98. 